\title{
Cold surge activity over the Gulf of Mexico in a warmer climate $^{1}$
}

\author{
Edgar P. Pérez ${ }^{1}$, Víctor Magaña ${ }^{2 *}$, Ernesto Caetano² and S. Kusunoki ${ }^{3}$ \\ ' Colegio de Ciencia y Tecnología, Universidad Autónoma de la Ciudad de México, Mexico City, Mexico \\ ${ }^{2}$ Geografia Fisica, Clima y Sociedad, Instituto de Geografía, Universidad Nacional Autónoma de México, Mexico City, Mexico \\ ${ }^{3}$ Climate Research Department, Meteorological Research Institute, Tsukuba, Japan
}

\section{Edited by:}

David Barriopedro, Universidad

Complutense de Madrid and

Instituto de Geociencias (CSIC,

UCM), Spain

\section{Reviewed by:}

Sagnik Dey, Indian Institute of

Technology Delhi, India

Ana María Durán-Quesada,

University of Costa Rica, Costa Rica

Zhong Liu, George Mason

University, USA

*Correspondence:

Víctor Magaña, Circuito de la Investigación Cientifica, Instituto de Geografía, Universidad Nacional Autónoma de México, Circuito

Exterior S/N, Coyoacan, Mexico City 04510, Mexico

e-mail:victormr@unam.mx
Cold surges are a dominant feature of midlatitude tropical interaction. During the North Hemisphere $(\mathrm{NH})$ winter, midlatitude waves propagating from the Rocky Mountains into the Gulf of Mexico result in cold surges, also known as Nortes or Tehuantepecers, associated with severe weather over the southern part of Mexico. The magnitude of their intense surface winds, precipitation and drops in surface temperature depends on the characteristics of the midlatitude wave propagating into the tropics. The high spatial resolution $(20 \times 20 \mathrm{~km})$ version of the TL959L60-AGC Model of the Meteorological Research Institute of Japan is used to examine changes in cold surge activity under the A1B greenhouse gas emission scenario for the 2080-2099 period. The model realistically reproduces the spatial and temporal characteristics of cold surges for the 1980-1989 control period. The effect of changes in baroclinicity, static stability and mean flow over North America suggest that in a warmer climate, increased cold surge activity over the Gulf of Mexico would occur. However, these systems would have shorter wavelength (higher phase speeds) and shorter lifespans that could reduce the total amount of winter precipitation. The increased frequency of cold surges over the Gulf of Mexico would be a consequence of weaker baroclinicity and static stability in the lower troposphere over the cold surge genesis region, along with more dominant westerly winds, resulting from ENSO-like conditions in the atmospheric circulations over North America.

Keywords: cold-surge, midlatitude-tropical interaction, climate change, El Niño, Gulf of Mexico

\section{INTRODUCTION}

Tropical and subtropical regions are frequently affected by winter surges of cold air that propagate from the midlatitudes, as a form of atmospheric midlatitude-tropical interactions (Colle and Mass, 1995). Cold surges over the Gulf of Mexico, also known as Nortes (Magaña et al., 2003) or Tehuantepecers (Trasviña et al., 1995), are related to masses of cold air and high surface pressure that originate over the northwestern parts of the Rocky Mountains (their genesis region) and move southeastward into the tropics. They produce air surface temperature drops as large as $20^{\circ} \mathrm{C}$ in $24 \mathrm{~h}$, in the Veracruz region (Figure 1) and precipitation of up to $200 \mathrm{~mm} \mathrm{day}^{-1}$ along the coastal zone of eastern Mexico, as well as intense gap winds over the Tehuantepec Isthmus (Henry, 1979; Schultz et al., 1997, 1998). Reding (1992) estimates that $70-90 \%$ of winter precipitation in the southern MexicoCentral American region is related to these phenomena. The strong winds associated with the cold surge over the Tehuantepec Isthmus may be between 10 to $20 \mathrm{~ms}^{-1}$, but with gust winds of up to $60 \mathrm{~ms}^{1}$, that result from the large meridional pressure gradient between the Gulf of Mexico and the northeastern tropical Pacific.

\footnotetext{
${ }^{1}$ The first author, Edgar P. Pérez, died in December 2010, after the first draft of this manuscript was completed. This work is now published as a memorial to him.
}

Their effects may last between 2 to 6 days, depending on the phase speed (wavelength) of the system (Schultz et al., 1998). On the average, 20-25 cold surges affect the Gulf of Mexico from October through March. However, there is substantial interannual variability in cold surge activity, mainly in relation to $\mathrm{El}$ Niño/Southern Oscillation (ENSO) (Magaña et al., 2003). During El Niño (La Niña), more (less) cold surges, with shorter (longer) than average wavelengths affect Mexico and faster (slower) phase speeds, leading to less (more) winter precipitation. The more frequent passage of cold surges over the Gulf of Mexico during El Niño is related to changes in the mean flow induced by the Pacific North American (PNA) pattern that affects the subtropical jet stream, forcing the mean flow into a more westerly state over this region (Magaña and Ambrizzi, 2005). This allows transients, such as cold surges, to propagate deep into lower latitudes, as in a westerly duct (Webster and Holton, 1982). Cold surges with higher phase speed (Vazquez, 1999) may result in negative precipitation anomalies during the Northern Hemisphere $(\mathrm{NH})$ winter over southeastern Mexico. Slower cold surges (longer wavelengths), produce precipitation for a longer period that frequently result in more rainfall, as in 1999 or 2007 (Landa et al., 2009).

As a result of climate change, the mean atmospheric meridional temperature gradient, the baroclinicity, the static stability and the mean flow are to be affected (e.g., Teng et al., 2008). These changes may have important consequences in climate at 


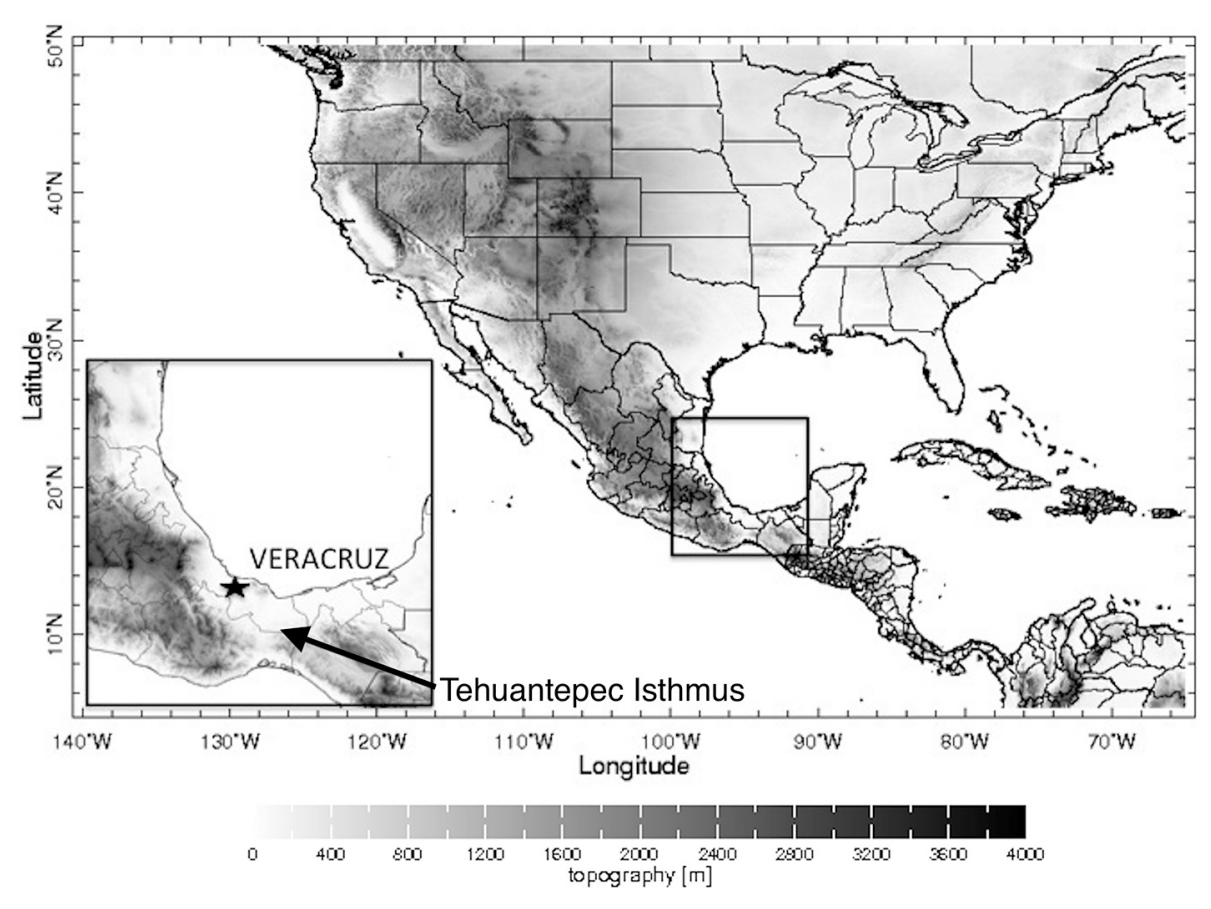

FIGURE 1 | Topography over North America. The location of the city of Veracruz, Mexico and the Tehuantepec Isthmus are indicated.

the regional level (IPCC, 2013) for instance, in the tropical Americas (Karmalkar et al., 2011), as they alter cold surge activity. Considering the importance of these phenomena for the winter climate in the Mesoamerica region, it is interesting to examine the dynamics involved in cold surge activity in a warmer climate. By means of climate change experiments baroclinicity, static stability and the mean flow over North America are diagnosed to determine how this may affect cold surge activity. The regional climate model TL959L60 AGCM from the Earth Simulator of the Meteorological Research Institute (MRI) of Japan, is a state of the art model that has proven to be an adequate tool to examine regional climate change signals (Kusunoki et al., 2006). In particular, it has shown high skill to reproduce present climate features over the tropical Americas (Perez et al., 2007), which makes it a valuable tool to interpret climate change simulations based on physical principles. Therefore, the main goal in the present paper is to explore changes in the mean atmospheric state of North America in order to determine the large-scale factors that control cold surge activity in a warmer climate and examine regional climate change signals.

In Section Data and Methodology, the paper describes the data and methodology used in the study. The main results of this work are given in Section Changes in Cold Surge Activity over the Gulf of Mexico in a Warmer Climate. Section Discussion presents a brief discussion of the results and conclusions are given in Section Conclusions.

\section{DATA AND METHODOLOGY THE TL959L60 AGCM}

The TL959L60 AGC regional climate model is part of the Earth Simulator and its characteristics, as well as its skill to simulate various atmospheric processes has been discussed in detail by
Mizuta et al. (2006). Kusunoki et al. (2006) have examined a very high spatial resolution $(20 \times 20 \mathrm{~km}, 60$ vertical levels $)$ control run for the present climate and for a climate under the IPCC SRES A1B greenhouse gas emissions scenario for the end of the twentyfirst century. Their TL959L60-AGC present climate experiment was conducted with observed climatological SSTs averaged from 1982 to 1993 and for the future climate experiment, the simulation was done using SSTs, projected with the MRI-CGCM2.3 (Yukimoto et al., 2006). Although they did only one climate change realization with this spatial resolution, they results serve for a process study to analyze regional climate change signals. The main goal of the present study is to examine the dynamical mechanisms that result in diminished $\mathrm{NH}$ winter precipitation over the central southern part of Mexico in relation to changes in cold surge activity.

In the preset study, 10 years of data of the TL959L60-AGC control (1980-1989) and future climate (2080-2089) experiments (Kusunoki et al., 2006) from October to March have been used to examine cold surge activity over the IAS. The model skill to simulate climate over Mexico has been examined by means of a comparison between present day simulations and gridded observed data (Perez et al., 2007). For instance, the orographic effect on the mean winter precipitation pattern for the present climate (Figure 2A) is reasonably reproduced by the model (Figure 2B). Winter precipitation over Mexico for the future climate (not shown) maintains the same spatial distribution, but compared with the present climate simulations it shows a reduction over the Veracruz region of the order of $0.5 \mathrm{~mm} /$ day (around 10\%) (Figure 2C). Since cold surge events produce most of the winter precipitation over the southern part of the Gulf of Mexico, it is likely that changes in such systems be responsible for such regional climate change. 

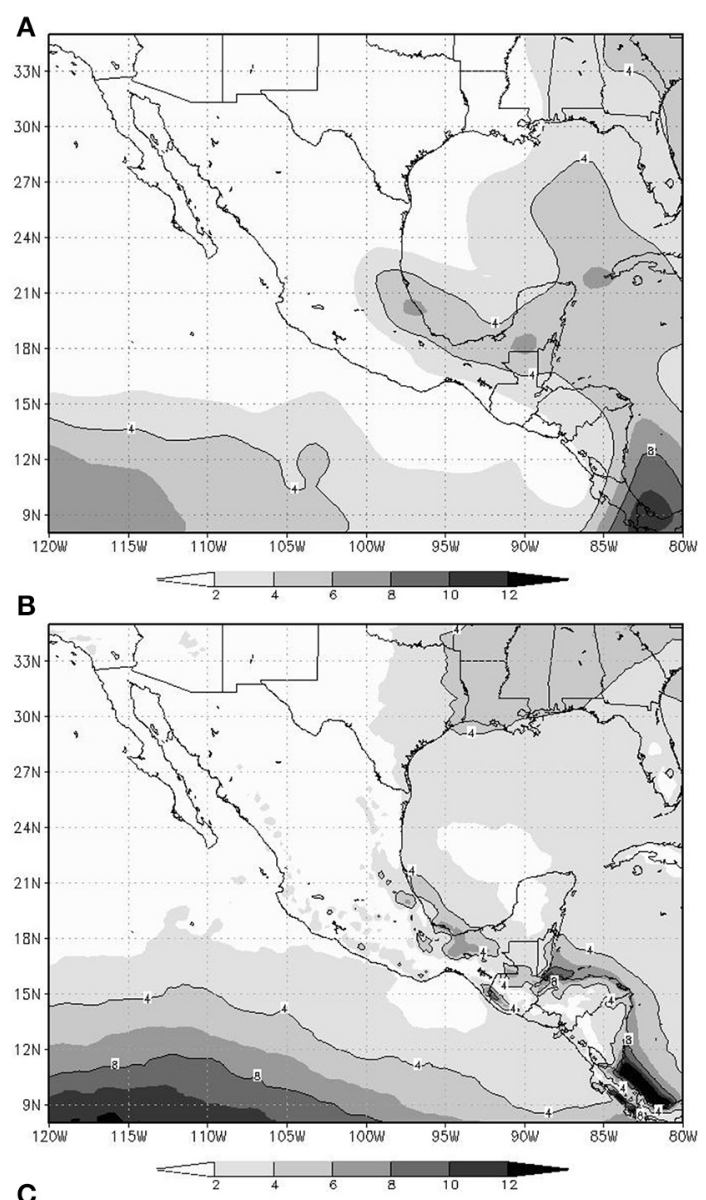

C

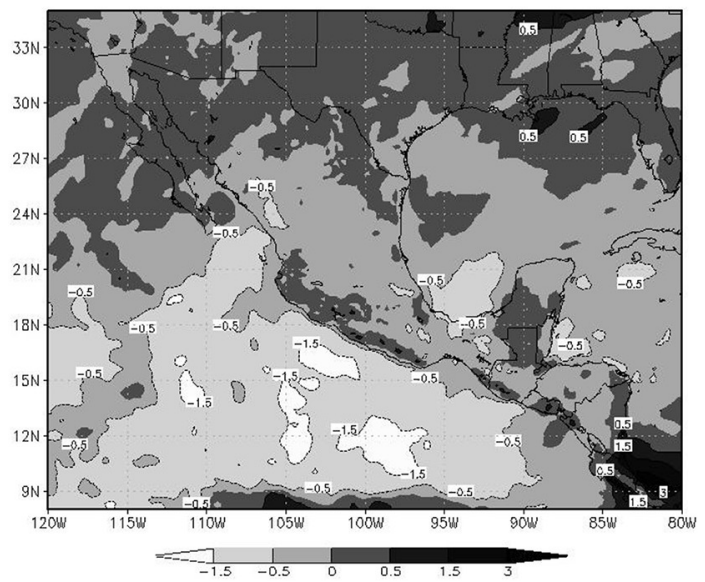

FIGURE 2 | Mean NH winter precipitation $\left(\mathrm{mm} \mathrm{day}^{-\mathbf{1}}\right)$. (A) Obtained from the NCEP/NCAR reanalysis for the 1980-1988 period, (B) as in (A), but obtained with the TL959L60 AGC model for the 1980-1989 period, and (C) Change in NH winter precipitation (mm day ${ }^{-1}$ ) for the 2080-2088, relative to 1980-1989 simulated with the TL959L60 AGC Model.

\section{COLD SURGE ACTIVITY OVER MEXICO}

Cold surges over the Gulf of Mexico have been characterized by means of various meteorological parameters such as surface pressure, intense winds, surface temperature drops or intense precipitation events (Reding, 1992; Schultz et al., 1997, 1998). Most of these meteorological signals are related to the meridional propagation of cold anticyclones that lead to intense northerly and northeasterly winds, large temperature drops and precipitation over the southern part of the Gulf of Mexico, as in Veracruz. Following Magaña (1999), a cold surge may be identified since it produces:

(1) Intense winds $(>10 \mathrm{~m} / \mathrm{s})$ with a northerly component over the Gulf of Mexico,

(2) temperature drops of $2^{\circ} \mathrm{C}$ or more in $24 \mathrm{~h}$ over the southeast coast of the Gulf of Mexico,

(3) precipitation over the southern Gulf of Mexico states.

Indices of these meteorological parameters over southern Mexico serve to construct composite maps of atmospheric patterns associated with the evolution of cold surges for the present and future climate. The model patterns of cold surges adequately compare with those obtained by Vazquez (1999) with NCAR/NCEP reanalysis data (Kalnay et al., 1996). Even more, the number of cold surge events compares well between with the observed one, i.e., around 25 events between October and March (Magaña, 1999).

In the present day experiment, cold surges present spatial and temporal characteristics similar to the observed ones. In this way, 2 days prior to the impact of a cold surge over Veracruz, there is a high-pressure system over the Rocky Mountains and dominant easterly flow over the Gulf of Mexico (Figure 3A). Gap flow over the Tehuantepec Isthmus is weak. As the midlatitude wave and the associated high-pressure system move southeastwards into the Gulf of Mexico, the mass of cold air interacts with the warm moist air of the Gulf of Mexico, resulting in a cold surge (Schultz et al., 1997). The anticyclonic circulation produces winds over the Gulf of Mexico, with a northerly component, that impacts the region of Veracruz (Figure 3B). The meridional pressure gradient between the high pressure in the northern part of the Gulf of Mexico and the lower surface pressure in the northeastern tropical Pacific generates intense gap winds across the Tehuantepec Isthmus, in southern Mexico. Mean maximum surface wind intensity over the southern Gulf of Mexico may exceed $15 \mathrm{~ms}^{-1}$. The cold surge produces intense precipitation along the frontal zone and along the eastern coast of Mesoamerica due to the orographic effect of the eastern Sierra Madre. As the midlatitude wave propagates eastwards (Figure 3C), the cold surge affects part of the Yucatan peninsula, Central America and the Caribbean Sea, but their effects weaken over the Veracruz region. The winds over the southern part of the Gulf of Mexico change from northerly to northeasterly.

Given the close resemblance between the cold surge (i.e., Norte) composite pattern produced by the regional climate model, in the present and future climate, and the observed patterns, it is feasible to examine the mean large scale atmospheric conditions in a future (warmer) climate that may affect the activity of such systems. 


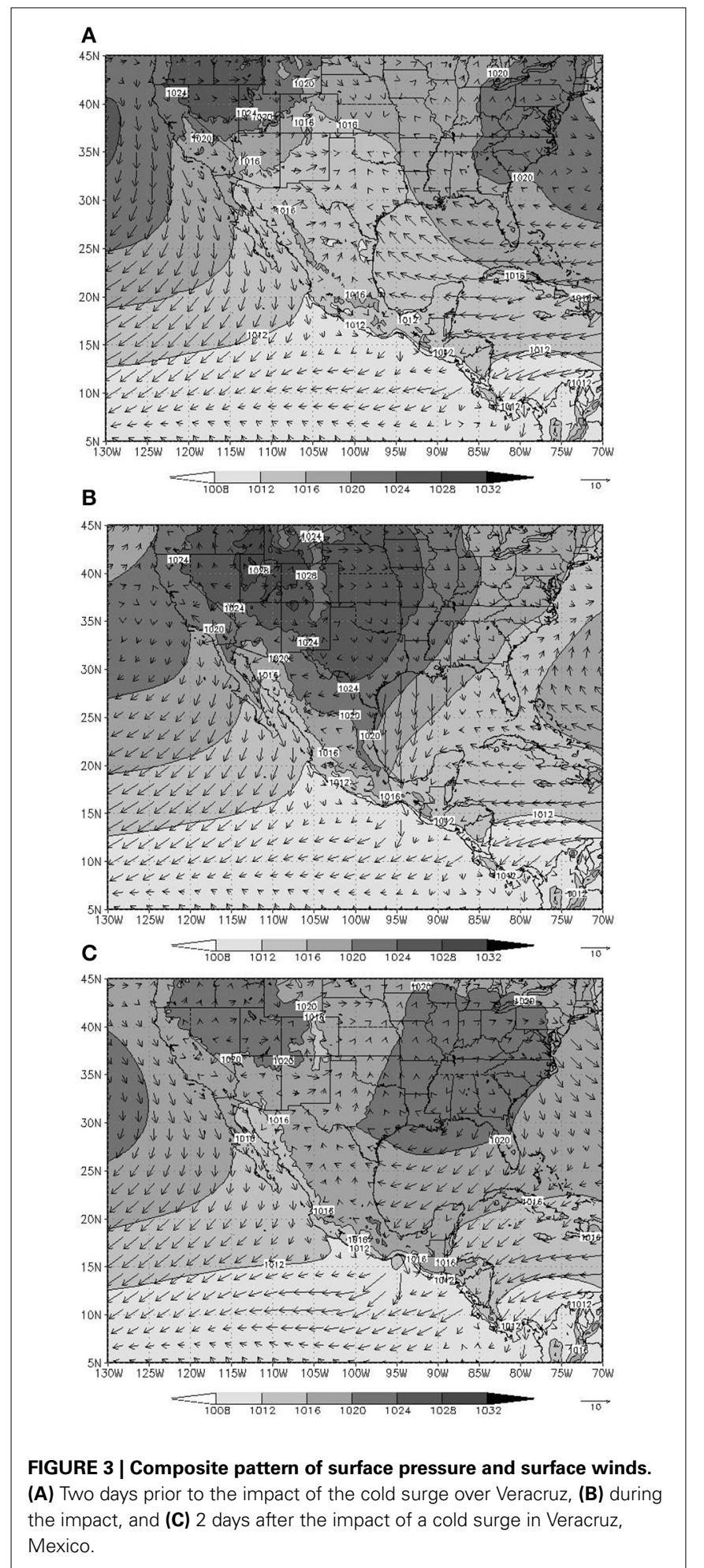

\section{CHANGES IN COLD SURGE ACTIVITY OVER THE GULF OF MEXICO IN A WARMER CLIMATE CHANGES IN COLD SURGE ACTIVITY}

The TL959L60-AGC model generates around 252 cold surge events for the 10 years period of the control run (around 25 per

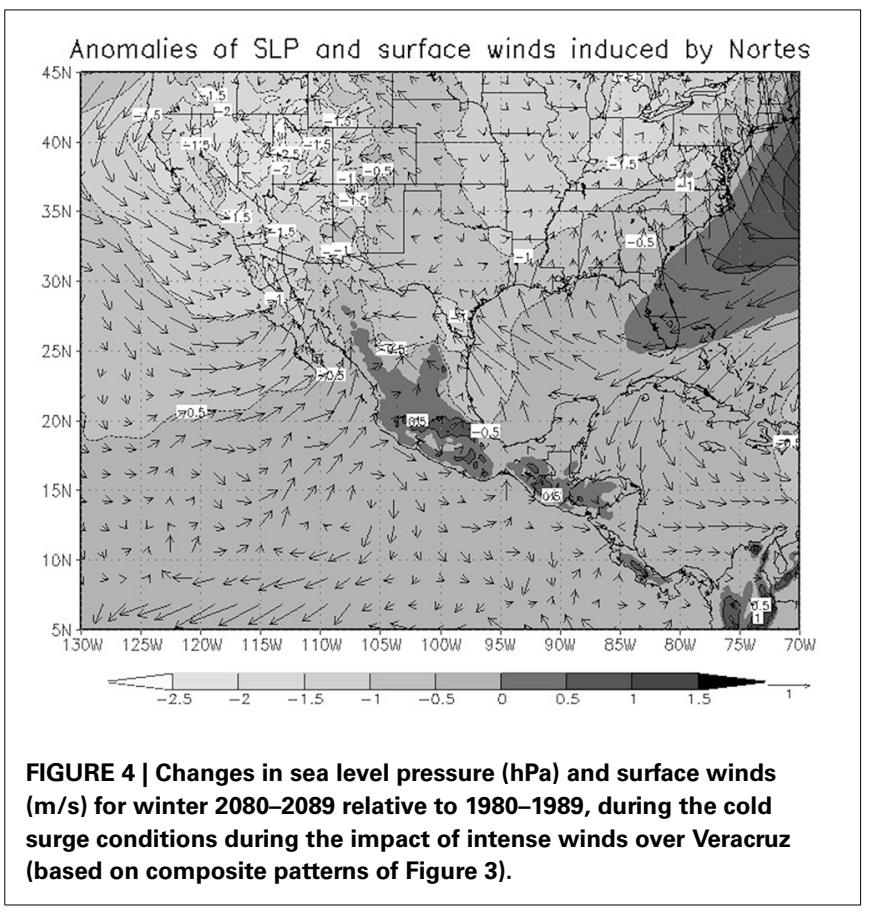

year), which compares fairly well with the 23 cases/year obtained with the NCAR/NCEP reanalysis (Kalnay et al., 1996)for the same 1980-1989 period (Magaña et al., 2003). For the future climate simulation, the model generates around 283 cold surges in 10 years (around 28 cold surges per year), which shows a slight increase of the synoptic wave activity over the Gulf of Mexico in a warmer climate. This increase in the number of cold surges may seem relatively small (around 10\%), but it is comparable to the interannual variability (Vazquez, 1999). Even more, the interannual variations in the number of cold surges may result in changes in winter precipitation in southern Mexico of $10-15 \%$, between dry and wet winters, as during El Niño and La Niña years. Since winter precipitation over the southern Gulf of Mexico region is less than average during El Niño, it is not only the number these systems, but also their characteristics what determine the amount of rainfall. For instance, in the warmer climate experiment, there is a tendency for the cold surge northerly winds to be weaker (Figure 4) which might reduce orographically forced precipitation. Cold surge precipitation also depends on the duration of the event, which in turns depends on the phase speed of the system.

Cold surge properties, such as their lifespan, intensity and surface temperature drops over the Gulf of Mexico, are related to changes in the characteristic wavelength of the associated midlatitude system that propagates into the tropics. Lifespan of a cold surge may be defined as the number of consecutive days during which the criteria defined in Section Data and Methodology for the impact over Veracruz are met. In the future (warmer) climate, cold surges are expected to be more frequent, but with shorter lifespans (Figure 5A). The percentage of systems inducing low temperature decreases $\left(<5^{\circ} \mathrm{C}\right)$ might increase, but a few more events with large temperature drops $\left(>8^{\circ} \mathrm{C}\right)$ might also occur (Figure 5B). The number of extremely intense northerly winds would also tend to decrease in a warmer climate (Figure 5C) with 

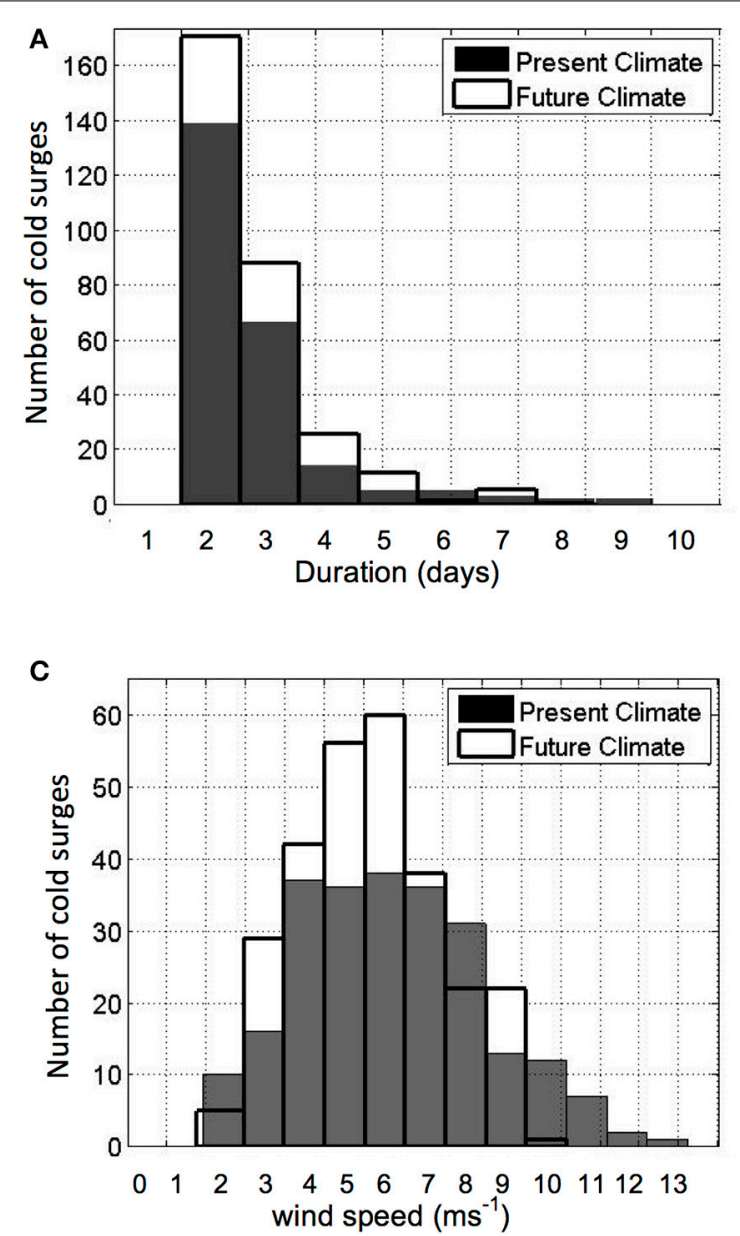

FIGURE 5 | Frequency of cold surges, computed from the TL959L60-AGCM for present and future (warmer) climate conditions, as a function of: (A) duration (days). (B) The associated temperature
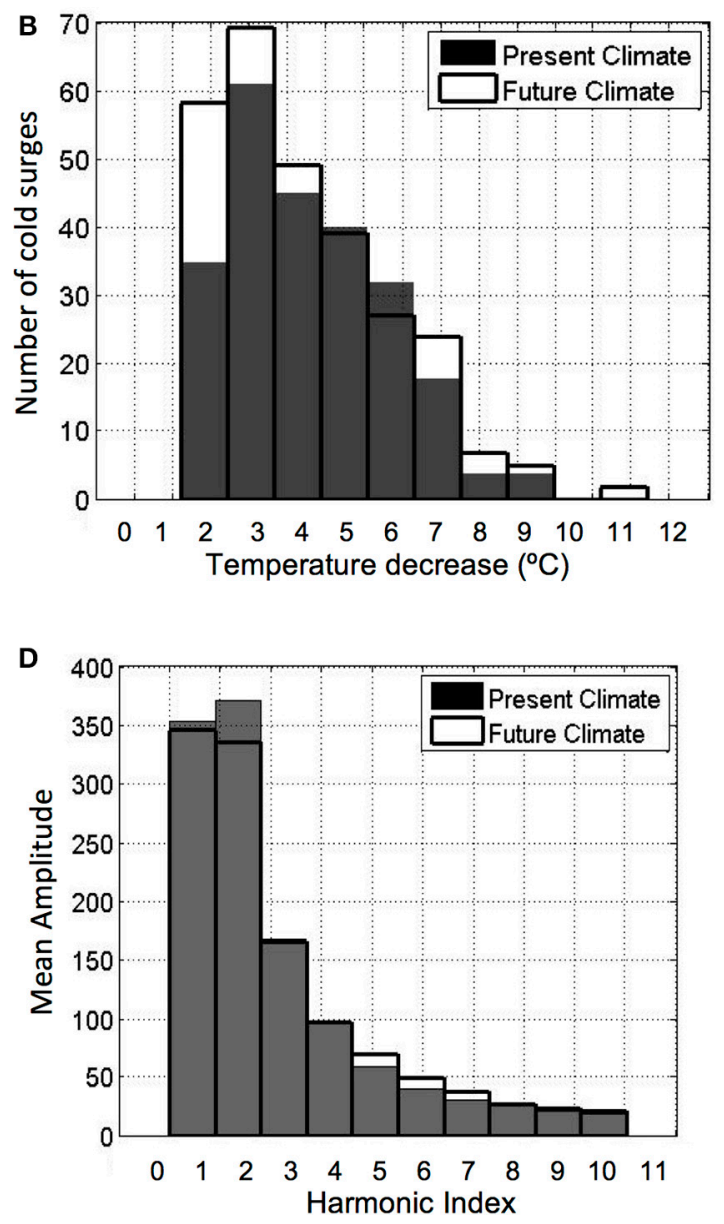

decreases $\left({ }^{\circ} \mathrm{C}\right)$, and (C) mean Norte surface winds $\left(\mathrm{ms}^{-1}\right)$. (D) Mean amplitude of the midlatitude wave at $500 \mathrm{hPa}$ (geopotential meters) associated with the cold surge as a function of the dominant wavelengths. wind speeds larger than $10 \mathrm{~ms}^{-1}$ becoming less frequent. The characteristic wavelength of the systems may be obtained by harmonic analyzing geopotential height at $500 \mathrm{hPa}$ over the domain of study $\left(18-29^{\circ} \mathrm{N}, 170-50^{\circ} \mathrm{W}\right)$. This analysis suggests for future climate conditions a decrease in the dominant zonal wavenumbers (1-2) within the domain, corresponding to wavelengths of approximately $12,200-6600 \mathrm{~km}$ of wavelength respectively. In the future climate, and a slight enhancement of the zonal wavenumbers 5-7, corresponding to zonal wavelengths of around $2000 \mathrm{~km}$ is expected (Figure 5D). Shorter wavelengths mean faster phase speeds and consequently shorter system lifespans (Figure 5A), and reduced precipitation periods. A dominance of shorter wavelength systems in the atmosphere is consistent with the dynamical response of a rotating flow, when the pole-equator temperature gradient is decreased (Hide et al., 1977). The tendency to have negative $\mathrm{NH}$ winter precipitation anomalies over the southern part of the Gulf of Mexico, is related to shorter wavelength systems propagating more rapidly from mid latitudes into the tropics with weaker Norte winds, as during an El Niño event (Magaña, 1999). Some of the driest winters in the southern part of Mexico tend to occur under El Niño conditions (Halpert and Ropelewski, 1992).

\section{CHANGES IN THE MEAN SST CONDITIONS}

In the climate change experiment with the TL959L60 AGC Model the imposed surface boundary conditions are important. The SST pattern in the future climate experiment (Figure 6) resembles El Niño conditions, with a dominant warm anomaly over the central eastern Pacific. This SST anomaly reflects in changes in the mean atmospheric state and consequently, in changes in cold surge activity in a similar way as during El Niño NH winter (Magaña et al., 2003).

The flow regimes that appear in a differentially heated rotating fluid are constrained mainly by the magnitudes of the thermal Rossby and Taylor numbers (Hide et al., 1977). If the poleequator temperature difference $\Delta \mathrm{T}$ decreases, while the other system parameters remain unchanged, the configuration in the fluid's regime diagram tends to shift to smaller thermal Rossby numbers, favoring weaker waves of higher wave numbers (i.e., shorter wavelengths). The mean temperature gradient in the 


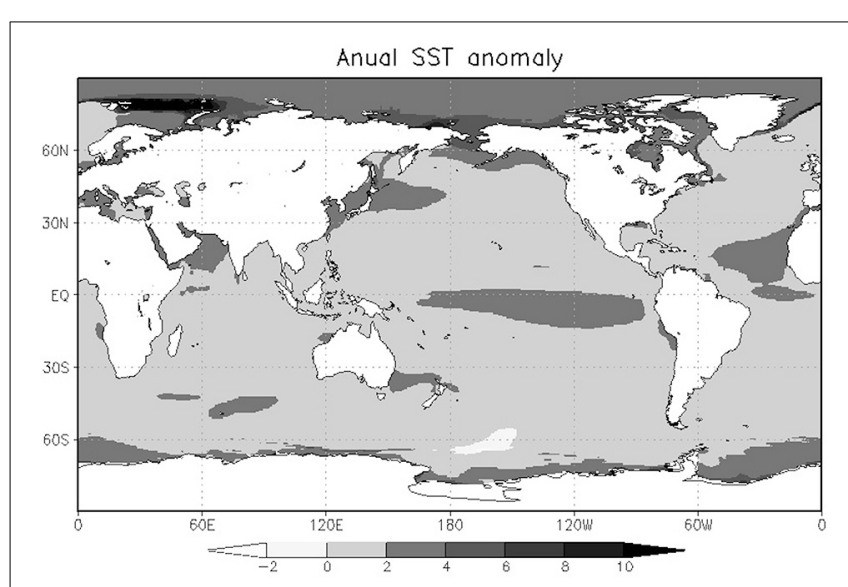

FIGURE 6 | Difference in the SSTs $\left({ }^{\circ} \mathrm{C}\right)$ used for present (1980-1989) and future (warmer) climate (2080-2089) model simulations.

numerical experiments shows a decrease in intensity as determined in the meridional temperature gradient over the domain of study (Figure 7).

This condition tends to produce a change in the dominant zonal wave numbers to shorter wavelengths (higher phase speed), which could explain the increased number of cold surges or Nortes in a warmer climate, as well as their shorter lifespans. However, the number of systems that form in the midlatitudes and propagate into the tropics, also depend on the atmospheric static stability, their evolution on the Eady growth rate and their propagation into the tropics in the characteristics of the mean flow.

\section{BAROCLINICITY AND ATMOSPHERIC STATIC STABILITY}

Baroclinic instability is the main source of energy for synoptic midlatitude systems. According to Van Loon (1967), a weaker meridional gradient of temperature, as that projected for a global warming scenario, would manifest in a local lower atmospheric baroclinic response with a consequent diminished midlatitude wave activity (Geng and Sugi, 2008). However, along with the meridional temperature gradient, the stability structure of a baroclinic atmospheric is relevant in inducing wave activity. Following Walland and Simmonds (1999), the baroclinicity of the atmosphere for present and future conditions, may be examined in terms of the meridional temperature gradient and the static stability of the atmosphere, considering the amplification rate of the most unstable baroclinic wave in the lower troposphere. Teng et al. (2008) found in one CCSM3 twenty-first century A1B scenario that there was significant increase in the extratropical cyclone frequency on the US west coast and decrease in Alaska. Lindzen and Farrell (1980), Walland and Simmonds (1999), and Teng et al. (2008), suggest that the baroclinicity of the atmosphere for present and future climate conditions can be determined considering the atmospheric static stability and the maximum Eady growth rate at the lower and middle troposphere.

Some theoretical experiments tend to show that waves belonging to the short-wave part of the spectrum of unstable waves are more sensitive to changes in the static stability parameter than waves belonging to the long-wave part of the spectrum

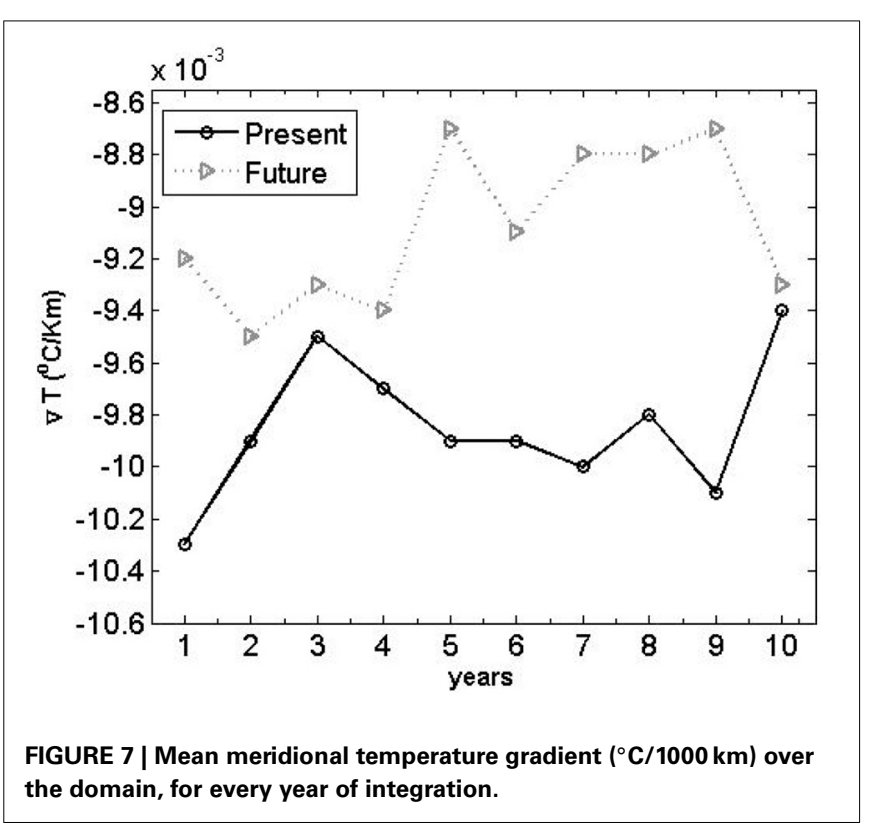

(Soldatenko and Tingwell, 2013). The model experiment for the future climate indicates that during the $\mathrm{NH}$ winter the static stability will decrease polewards and increase equatorwards in the lower troposphere (Figure 8). In particular, there is a decrease in static stability over the northern Rocky Mountains region, i.e., the cold surge genesis region. A lower vertical stability condition implies that a given meridional temperature gradient, even if weak, would have greater impacts, in terms of baroclinic instability, than a stronger gradient would have in the presence of higher atmospheric static stability conditions. In other words, contrary to the present climate conditions where both, the meridional temperature gradient and the atmospheric static stability are high, over the cold surge genesis region the increasing frequency of Nortes in a warmer climate may follow from a weaker atmospheric stability in midlatitudes even with a weaker meridional temperature gradient.

Since the wavelength of maximum instability is proportional to the ratio of static stability to the square of the rotation rate (Holton, 1992), lower static stability conditions north of $50^{\circ} \mathrm{N}$ mean that the wave number of maximum instability increases over that region (i.e., the wavelength decreases) and then shorter life-span systems would dominate at the cold surge genesis region. Furthermore, since baroclinic waves with shorter wavelengths are rather inefficient for the vertical and horizontal transport of heat, they feed back to the mean flow the weaker static stability conditions where they onset. The Eady growth rate $(\sigma)$ may be expressed as (Eady, 1949):

$$
\sigma=0.3098 f|\partial \mathrm{U}(\mathrm{z}) / \partial \mathrm{z}| N^{-1},
$$

where $N$ is the Brunt-Vaisala frequency, 0.3098 is a nondimensional coefficient, $f$ is the Coriolis parameter, and $U(z)$ is the vertical structure of the zonal wind. This expression of the maximum Eady growth rate is similar to Teng et al.'s (2008). In the TL959L60-AGC model, baroclinicity changes in the future 


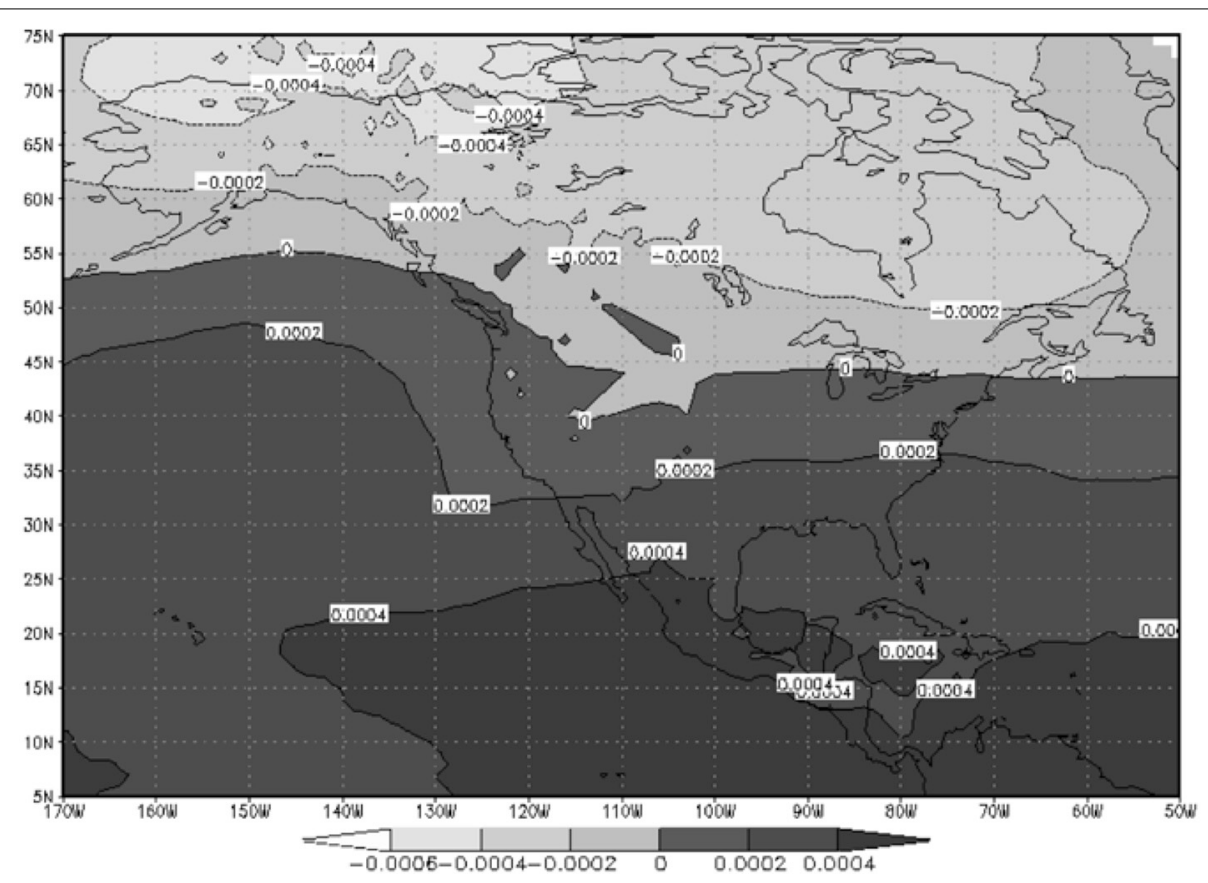

FIGURE 8 | Change of static stability $\left(\mathrm{K} \mathrm{hPa}^{-1}\right)$ between 850 and $500 \mathrm{hPa}$ for the $\mathrm{NH}$ winter (2080-2089) conditions minus (1980-1989) conditions.

climate simulation are small over the most of North America (Figure 9). In the warmer climate, baroclinicity tends to be weaker over western Canada and most of the US, along the path followed by synoptic waves that penetrate into the Gulf of Mexico. In this region, weaker baroclinicity but weaker static stability favors the more frequent genesis of shorter wavelengths that move into the Gulf of Mexico at higher phase speeds, as diagnosed (Figure 5).

The alterations to the atmospheric baroclinic instability resulting from the relationship between lower temperature gradients and weaker vertical stability conditions are such that the perturbations in the zonal flow tend to shift to higher frequencies and shorter wavelengths. The Eady growth rate how well deep pressure systems can develop in a weather situation over a specific area. Over most of North America, it tends to decrease (Figure 9) indicating more favorable conditions for the development of midlatitude waves of the kind that result in cold surges over the Gulf of Mexico.

\section{CHANGES IN THE MEAN FLOW}

Most model projections of climate change agree that there is a southeastward extension of the upper troposphere Pacific jet stream at the jet exit region, triggered by a sort of PNA pattern (Figure 10). This El Niño-like anomalous pattern might be responsible of the significant impacts on the West Coast midlatitude wave activity (Teng et al., 2008). The change of the $500 \mathrm{hPa}$ wind field in winter 2080-2089 relative to 1980-1989 (Figure 10) resembles some of the changes observed under El Niño conditions (Magaña et al., 2003). During El-Niño years, the anomalous convective heating over the central/eastern Pacific also generates a quasi-stationary Rossby wave known as the Pacific North America
(PNA) pattern (Horel and Wallace, 1981), with cyclonic circulations off the coast of California and the northern coast of the Gulf of Mexico. A PNA pattern appears to form during the NH winter season in the global warming TL959L60-AGC experiment. This pattern enhances the subtropical jet-stream, with a westerly anomaly over the Gulf of Mexico that allows the propagation of Rossby waves deep into the tropics (Webster and Holton, 1982). In the present case, the changes in the atmospheric circulation would favor the intrusion of cold surges over the IAS.

The change in the mean winter circulation at $500 \mathrm{hPa}$ under climate change conditions is qualitatively similar to the winter anomalous circulation observed during the El Niño in which the PNA pattern dominates and the subtropical jet stream shifts southwards and extends eastward promoting that more frontal systems and cold surges propagate to the Gulf of Mexico states and the Caribbean Sea.

\section{DISCUSSION}

Relating projected changes in regional climate to those associated with global warming requires a study of dynamical processes. The TL959L60-AGC climate model shows skill in reproducing the atmospheric circulations that result in the winter precipitation patterns over Mexico, mainly in relation to cold surge activity. A global warming projection experiment during the $\mathrm{NH}$ winter season has been analyzed and compared with a present climate control run to explain changes in precipitation over southern Mexico by means of examining changes in the midlatitude waves that propagate into the tropics over the Gulf of Mexico. The precipitation scenario suggests a decrease in $\mathrm{NH}$ winter precipitation in a warmer climate in the southern part of the Gulf of Mexico. In the future (warmer) climate scenario, midlatitude 


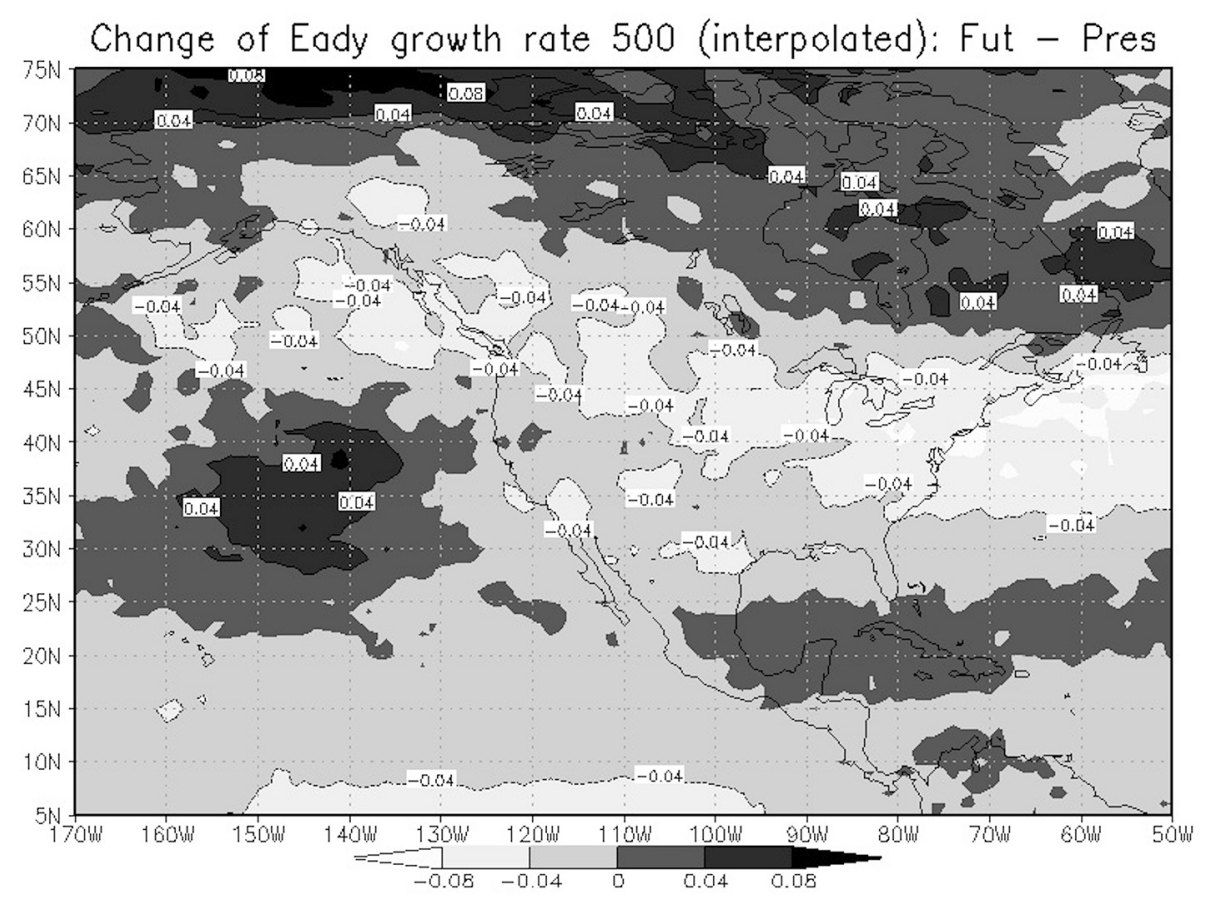

FIGURE 9 | Change of maximum Eady growth rate $\left(\right.$ day $^{-1}$ ) at $500 \mathrm{hPa}$ for the NH winter (2080-2089) minus (1980-1989).

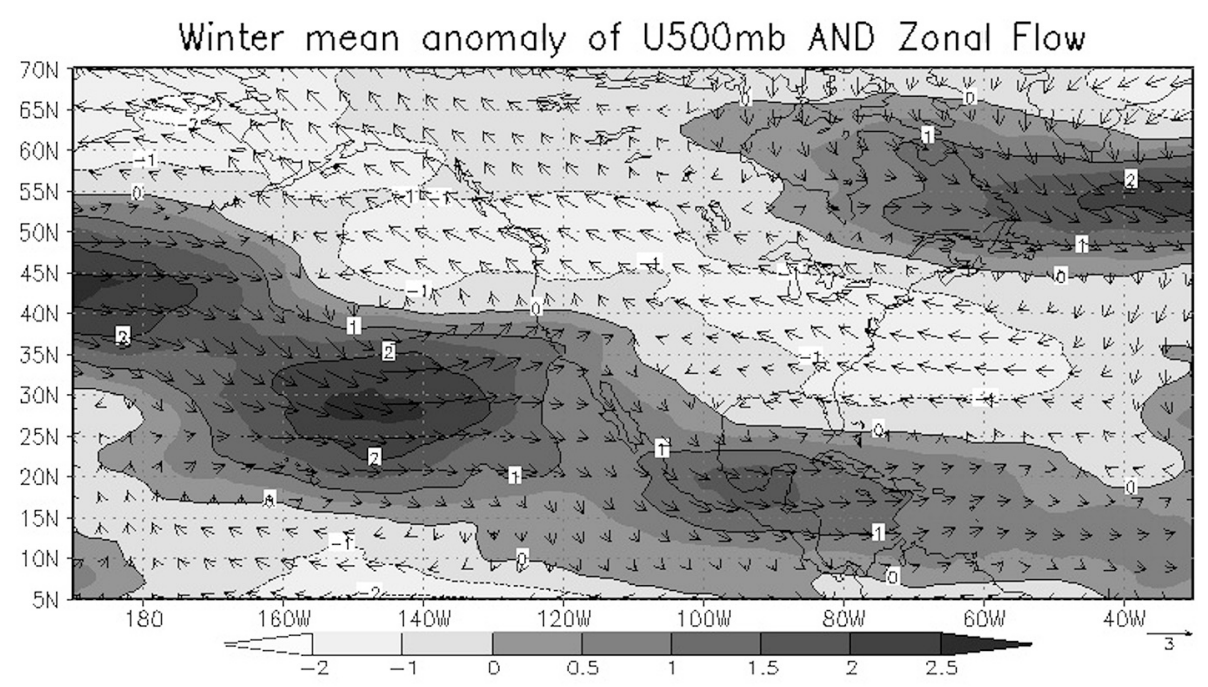

FIGURE 10 | Change of the $\mathbf{5 0 0 ~} \mathbf{h P a}$ wind $\left(\mathrm{ms}^{-1}\right)$ field for the NH winter 2080-2089 relative to 1980-1989. Shades indicate the corresponding anomalies in the $500 \mathrm{hPa}$ zonal flow.

waves propagating into the IAS with shorter wavelengths become more frequent than in present climate and result in shorter lifespans of the systems, as they have a faster phase speed over the Gulf of Mexico. The more frequent occurrence of faster moving cold surges appears to reduce the duration of winter rainfall and translates in less winter precipitation.

The projected characteristics of the midlatitude waves are due to changes in the meridional temperature gradient and the atmospheric static stability. With lower baroclinicity and lower static stability in the cold surge genesis region, shorter wavelength systems tend to develop and are favored by a lower Eady growth rate. On the other hand, the ENSO like condition used in the future climate experiment results in anomalous westerly atmospheric circulations over the IAS that favor the propagation of more (faster) cold surges into the tropics. The increasing activity of cold surges in the global warming projection tends to produce less winter precipitation in the southern part of the Gulf of Mexico. Trend analyses of precipitation for the twentieth century 
indicate a slight decrease in precipitation over the southern part of Mexico. However, the present study does not constitute an attribution experiment.

\section{CONCLUSIONS}

In the present study, a robust large-scale response of the atmosphere to increased radiative forcing, which corresponds to a warmer global climate, has been used to provide support to the regional signal of projected decrease in winter precipitation at the regional level in southern part of Mexico. The generation of local or regional climate change scenarios has been one of the main goals in the climate community to build a bridge with those interested in climate change impact scenarios. It is by means of dynamical analyses that relate the local characteristics of climate to large scale processes, that confidence may be gained in climate change projections at the regional level.

The present study takes advantage of the skill of the high spatial resolution model in simulating present day winter climate to analyze how large scale processes may determine climate change at the regional level. It is clear that for a more conclusive answer to the challenge of regional climate change scenarios, one should explore an ensemble of experiments. Such set of realizations with the Earth Simulator is available at a coarser spatial resolution and it may be worth exploring the robustness of the signal examined in this work. There are several studies that address the issue in mildatitude wave activity under climate change (Meehl et al., 2007; Teng et al., 2008), but only a few examine the potential changes in tropical midlatitude interactions in a warmer climate as a process study. This type of analyses may serve to gain confidence in the elements that may determine the signals of climate change in particular regions.

\section{ACKNOWLEDGMENTS}

This work was supported by Instituto Nacional de Ecología, Mexico during the year 2010 with a special grant from the World Bank, and the kind support of the Japan International Cooperation Agency (JICA). Special thanks to the Meteorological Research Institute of Japan for kindly providing the climate change TL959L60-AGC model experiments. The development of the present work is also possible thanks to the financial support of the National Autonomous University of Mexico through PAPIIT grants. We are indebted to Matías Méndez, for technical support and to Gustavo Vázquez and Nuria Vargas for preparing the manuscript in its final form.

\section{REFERENCES}

Colle, B. A., and Mass, C. F. (1995). The structure and evolution of could surges east of the Rocky mountains. Mon. Weather Rev. 123, 2577-2610.

Eady, E. (1949). Long waves and cyclone waves. Tellus 1, 33-52. doi: 10.1111/j.21533490.1949.tb01265.x

Geng, Q., and Sugi, M. (2008). Possible change of extratropical cyclone activity due to enhanced greenhouse gases and sulfate aerosols -Study with a high-resolution AGCM. J. Climate 16, 2262-2274. doi: 10.1175/15200442(2003)162.0.CO;2

Halpert, M. S., and Ropelewski, C. F. (1992). Surface temperature patterns associated with the Southern Oscillation. J. Climate 5, 577-593.

Henry, W. K. (1979). Some aspects of the fate of cold fronts in the Gulf of Mexico. Mon. Weather Rev. 107, 1078-1082.
Hide, R., Mason, P. J., and Plumb, R. A. (1977). Thermal convection in a rotating fluid subject to a horizontal temperature gradient: spatial and temporal characteristics of the fully-developed baroclinic waves. J. Atmos. Sci. 34, 930-950.

Holton, J. R. (1992). An Introduction to Dynamic Meteorology, 3rd Edn. New York, NY: Academic Press.

Horel, J. D., and Wallace, J. M. (1981). Planetary-scale atmospheric phenomena associated with the Southern Oscillation. Mon. Weather Rev. 109, 813-829.

IPCC. (2013). "Climate change 2013: the physical science basis," in Contribution of Working Group I to the Fifth Assessment Report of the Intergovernmental Panel on Climate Change, eds T. F.Stocker, D. Qin, G.-K. Plattner, M. Tignor, S. K. Allen, J. Boschung, et al. (Cambridge; New York: Cambridge University Press), 1535.

Kalnay, E., Kanamitsu, M., Kistler, R., Collins, W., Deaven, D., Gandin, L., et al. (1996). The NCEP/NCAR 40-year reanalysis project. Bull. Am. Meteorol. Soc. 77, 437-471. doi: 10.1175/1520-0477(1996)077\%3C0437:TNYRP\%3E2.0.CO;2

Karmalkar, A. V., Bradley, R. S., and Diaz, H. F. (2011). Climate change in Central America and Mexico: regional climate model validation and climate change projections. Clim. Dyn. 37, 605-629. doi: 10.1007/s00382-011-1099-9

Kusunoki, S., Yoshimura, J., Yoshimura, H., Noda, A., Oouchi, K., and Mizuta, R. (2006). Change of Baiu rain band in global warming projection by an atmospheric general circulation model with a $20-\mathrm{km}$ gris size. J. Meteorol. Soc. Jpn. 84, 581-611 doi: 10.2151/jmsj.84.581

Landa, R., Magaña, V., and Neri, Y. C. (2009). Clima y Agua: Elementos Para la Adaptación al Cambio Climático. Mexico City: SEMARNAT

Lindzen, R. S., and Farrell, B. F. (1980). A simple approximate result for maximum growth rate of baroclinic instabilities. J. Atmos. Sci. 37, 1648-1654.

Magaña, R. V. (1999). Los Impactos del El Niño en México. Mexico City: SEPCONACYT.

Magaña, V., and Ambrizzi, T. (2005). Dynamics of subtropical vertical motions over the Americas during El Niño boreal winters. Atmosfera 18, 211-234.

Magaña, V., Vázquez, J., Pérez, J. L., and Pérez, J. B. (2003). The Impact of El Niño on precipitation in Mexico. Geofísica Int. 42, 313-330.

Meehl, G. A., Covey, C., Taylor, K. E., Delworth, T., Stouffer, R. J., Latif, M., et al. (2007). THE WCRP CMIP3 Multimodel Dataset: a new era in climate change research. Bull. Am. Meteorol. Soc. 88, 1383-1394. doi: 10.1175/BAMS-889-1383

Mizuta, R., Oouchi, K., Yoshimura, H., Noda, A., Katayama, K., Yukimoto, S., et al. (2006). $20 \mathrm{~km}$-mesh global climate simulations using JMA-GSM model-Mean Climate States-. J. Meteor. Soc. Japan, 82, 1187-1211.

Perez, E., Méndez, J. M., and Magaña, V. (2007). "High spatial resolution climate change scenarios for Mexico based on experiments conducted with the Earth simulator," in Visualizing Future Climate in Latin America: Results From the Application of the Earth Simulator, Latin America and Caribbean Region Sustainable Development Working Paper 30, ed W. Vergara (Washington, DC: The World Bank Latin America and the Caribbean Region Sustainable Development Department (LCSSD)).

Reding, P. J. (1992). The Central American Cold Surge: an Observational Analysis of the Deep Southward Penetration of North America Cold Fronts. MSc. thesis, Department of Meteorology, Texas A\&M University. Available online at: http:// www.dtic.mil/dtic/tr/fulltext/u2/a268592.pdf

Schultz, D. M., Bracken, W. E., and Bosart, L. F. (1998). Planetary and synoptic scale signatures associated with Central American cold surges. Mon. Weather Rev. 126, 5-27.

Schultz, D. M., Bracken, W. E., Bosart, L. F., Hakim, G. J., Bedrick, M. A., Dickinson, M. J., et al. (1997). The 1993 superstorm cold surge: Frontal structure, gap flow, and tropical impact. Mon. Weather Rev. 125, 5-39.

Soldatenko, S., and Tingwell, C. (2013). The sensitivity of characteristics of large scale baroclinic unstable waves in southern hemisphere to the underlying climate. Adv. Meteorol. 2013, 981271. doi: 10.1155/2013/981271

Trasviña, A., Barton, E. D., Brown, J., Velez, H. S., Kosro, P. M., and Smith, R. L. (1995). Offshore wind forcing in the Gulf of Tehuantepec, Mexico: the asymmetric circulation. J. Geophys. Res. 100, 20649-20663.

Teng, H., Washington, W. M., and Meehl, G. A. (2008). Interannual variations and future change of wintertime extra-tropical cyclone activity over North America in CCSM3. Clim. Dyn. 30, 673-686. doi: 10.1007/s00382-007-0314-1

Van Loon, H. (1967). The half yearly oscillations in middle and high southern latitudes and the coreless winter. J. Atmos. Sci. 24, 472-486.

Vazquez, A. J. (1999). Caracterización Objetiva de Los Cold Surges Del Golfo de México y su Variabilidad Interanual. BSc. thesis, Universidad Veracruzana. 
Walland, D., and Simmonds, I. (1999). Baroclinicity, meridional temperature gradients, and the southern semiannual oscillation. J. Clim. 12, 3376-3382.

Webster, P. J., and Holton, J. R. (1982). Wave propagation through a zonally varying basic flow: the influences of mid-latitude forcing in the equatorial regions. $J$. Atmos. Sci. 39, 722-733.

Yukimoto, S., Noda, A., Kitoh, A., Hosaka, M., Yoshimura, H., Uchiyama, T., et al. (2006). Present-day climate and climate sensitivity in the Meteorological Research Institute Coupled GCM version 2.3 (MRI-CGCM2.3). J. Meteorol. Soc. Jpn. 84, 333-363. doi: 10.2151/jmsj.84.333

Conflict of Interest Statement: The authors declare that the research was conducted in the absence of any commercial or financial relationships that could be construed as a potential conflict of interest.
Received: 27 April 2014; accepted: 23 July 2014; published online: 12 August 2014. Citation: Pérez EP, Magaña V, Caetano E and Kusunoki S (2014) Cold surge activity over the Gulf of Mexico in a warmer climate. Front. Earth Sci. 2:19. doi: 10.3389/feart. 2014.00019

This article was submitted to Atmospheric Science, a section of the journal Frontiers in Earth Science.

Copyright (c) 2014 Pérez, Magaña, Caetano and Kusunoki. This is an open-access article distributed under the terms of the Creative Commons Attribution License (CC BY). The use, distribution or reproduction in other forums is permitted, provided the original author(s) or licensor are credited and that the original publication in this journal is cited, in accordance with accepted academic practice. No use, distribution or reproduction is permitted which does not comply with these terms. 